\title{
Author Correction: Evidence for large microbial-mediated losses of soil carbon under anthropogenic warming
}

Pablo García-Palacios (1D, Thomas W. Crowther (1), Marina Dacal(D), Iain P. Hartley (D), Sabine Reinsch, Riikka Rinnan (1), Johannes Rousk(D), Johan van den Hoogen, Jian-Sheng Ye and Mark A. Bradford

Correction to: Nature Reviews Earth \& Environment https://doi.org/10.1038/s43017-021-00178-4, published online 15 June 2021.

In the original published article, the graphs in Figure 2 were incorrectly based on soil carbon density per soil mass, not soil carbon stocks per area as the axis labels indicated. Figure 2 and the legend have been updated to now reflect the use of soil carbon stock per unit area data. These changes do not affect the findings of the Perspective. These errors have been corrected in the HTML and PDF versions of the manuscript.

https://doi.org/10.1038/s43017-021-00197-1 I Published online 29 June 2021

(C) Springer Nature Limited 2021 